\title{
Social Business Process Management and Knowledge Intensive Processes
}

\author{
Vesna Bosilj Vukšić \\ University of Zagreb, Faculty of Economics \& Business, Croatia \\ Dalia Suša \\ University of Zagreb, Faculty of Economics \& Business, Croatia \\ Anita Lovrić \\ Infodom, Croatia
}

\begin{abstract}
Business process management (BPM) is a worldwide spread holistic management discipline which increases organizational performance by managing its business processes. A number of researchers indicate the need for further examination of the role of organizational culture in BPM and its maturity. In addition, there has been a recent development of social BPM as an effort to overcome the traditional BPM limitations by using social software for managing the organizations' business processes and increasing collaboration between BPM project teams. Therefore, we conducted a case study in one Croatian IT company which operates as a consultant company and deals with software implementation. Since their processes are knowledge intensive, they are not always formal and structured so social BPM helps the company with process change and optimization. The aim of this paper is to examine the role of organizational culture and social software usage on BPM maturity in the observed company.
\end{abstract}

Keywords: social business process management, knowledge intensive processes, business process management maturity, organizational culture, society, case study, Croatia JEL classification: M15

\section{Introduction}

According to Hammer (2007) Business Process Management (BPM) is increasingly being seen as a mechanism for achieving competitive advantage through performance improvement by adopting a process view of business. However, recent work has revealed a growing awareness of the shortcomings of classical BPM approaches. A new term - "social BPM (SBPM)" is introduced. It describes the fusion of traditional BPM with social media applications like wikis, blogs, forums or social networks. The aim of SBPM is to enhance BPM lifecycle by means of controlled participation of external stakeholders from the initial stages of process discovery all the way to final phases of BPM life cycle, such as the phases of process execution and evaluation (Dengler et al., 2010; Erol et al., 2010). Besides, a number of researchers indicate the need for further examination of the role of organizational culture in BPM and its maturity (Rosemann and vom Brocke, 2015, Buh et al., 2015).However, further empirical confirmation of those theses should be made. Therefore the research goal of this study is to examine the role of organizational culture and social software usage on BPM maturity in a Croatian IT company.

This work has been fully supported by Croatian Science Foundation under the project PROSPER - Process and Business Intelligence for Business Performance (IP- 
2014-09-3729). Among others, two objectives of the PROSPER project are(1) to investigate the adoption of social BPM in organizations and (2) to explore different combinations of organizational culture types and different business process maturity levels. With the purpose to achieve stated objectives, the PROSPER research group conducted a series of interviews. One of them is being presented in this paper in form of a case study.

The structure of the paper is as follows: next section provides the theoretical background, defining BP holistic approach. In this section a BPM maturity model developed by Rummler-Brache Group (Process Performance Index - PPI) is described. Besides, this part of the paper brings a brief literature review on the organizational culture in BPM and presents the Organizational Culture Assessment Instrument. The third section describes a case study of Croatian IT company. Further, the analysis of the research results is presented. In the final section there is a short conclusion with the research limitations and plan for future research.

\section{BPM as a holistic concept}

There is an increasing number of authors accepting and emphasizing the holistic approach to BPM. The holistic nature of BPM requires alignment to corporate goals and strategy, focus on customers, top management commitment, process measurement, improvement and benchmarking. This approach is reflected within the design of BPM maturity models.

During the decades numerous authors developed, described and compared different BPM maturity models (Harmon, 2009; Rosemann and vom Brocke, 2015). In this research Process Performance Index (PPI) developed by Rummler-Brache Group (2004) is used. Respondents state their level of agreement on a 5-point scale for ten success factors, being: (1) alignment with strategy, (2) holistic approach, (3) process awareness by management and employees, (4) portfolio of process management initiatives, (5) process improvement methodology, (6) process metrics, (7) customer focus, (8) process management, (9) information systems and (10) change management. The cumulative score for an organization represents its PPI which describes three levels of BPM maturity: (1) process management initiation (PPI from 10 to 25 points); (2) process management evolution (PPI from 26 to 40); and (3) process management mastery (PPI from 41 to 50).

There have been numerous researches indicating the influence of organizational culture to BPM (e.g. Alibabaei et al., 2010; Rosemann and vom Brocke, 2015; Buh et al., 2015). In the sense of holistic BPM approach organizational culture is a critical BPM success factor (Rosemann and de Bruin, 2005). In accordance to that, Sidorova and Isik (2010), view it as a central issue in the implementation of BPM. Hribar and Mendling (2014) reported clan culture to be the most favorable when it comes to BPM adoption. Zairi (1997) introduced specific BPM culture, but never elaborated that idea. However, Schmiedel et al. (2013) conducted a global Delphi study and defined four key values for BPM culture, being: (1) customer orientation, (2) excellence, (3) reliability and (4) teamwork. For the purpose of this research, we use Organizational Culture Assessment Instrument (OCAl), developed by Cameron and Quinn (2006) to assess the current organizational culture of our respondents' organizations. Originally, OCAl assesses both the current and preferred organizational culture of the organizations. Respondents divide 100 points between 4 statements in each of the six groups of statements. In each group each statement represents one of the four types of organizational culture, being: (1) clan, (2) adhocracy, (3) market and (4) hierarchy. 


\section{Social BPM}

Today, a feedback from business practice reports on the shortcomings of classical BPM approaches. Several issues have been identified. "The model-reality divide" describes the divide between abstract process models and the processes executed in practice (Schmidt and Nurcan, 2009). According to Bidder et al. (2010) this issue specially concerns loosely structured and evolutionary processes, also known as knowledge-intensive processes. These processes typically appear in many scenarios, their sequences and participants are not known in advance, they involve distributed and evolving knowledge and have a high interactivity (Markus et al., 2002; Bögel ef al, 2013). The next issue is related to the incapability of BPM to react quickly to external and internal events (Cummins, 2008). The standard BPM lifecycle consists of a number of phases that follow ordered steps and procedures while the flow of information and the role of the participants are rigidly defined (Nurcan et al., 2008; Bruno et al, 2011). Besides, the pre-defined BPM roles and actors could impede the flow of information and knowledge sharing among stakeholders. "Loss of innovation" and "information pass-on threshold" are issues described by Schmidt and Nurcan (2009).

Nowadays, in order to overcome these situations, the researchers propose the integration of social software in the BPM lifecycle (Brambilla et al., 2012; Rangiha and Karakostas, 2013; Khider and Benna, 2015). The aim is to overcome the limitations with the traditional BPM by deploying social software and the collaborative Web (Web 3.0) as a platform for collaboration between individuals and groups in BPM projects (Rangiha and Karakostas, 2013; 2014). According to Meske and Stieglitz (2013) social media enable participation of all members of an organization and improve a company's knowledge management.

\section{Methodology}

For the purpose of this paper, a case study methodology has been employed as a suitable approach in examining the connection between process maturity, social BPM and organizational culture. Case study as a methodology has been previously verified as a valid research method, especially for exploratory researches (Yin, 1994).

The case study of a Croatian IT company presented in this paper is based on the interview which has been conducted in February 2016 as part of exploratory analysis for the evaluation of the draft version of questionnaire within the PROSPER project. As an appropriate case, we sought a company in the IT sector that has knowledge intensive business processes and had engaged in a BPM project in the past five years. A special focus is put on the organizational culture as a driver of BPM implementation success. The interviewees were executives familiar with the BPM implementation progress. The interview lasted about 3 hours and consisted of two parts: (1) a semi-structured interview and (2) in-depth interview.

First, the interviewees evaluated the statements of PPI framework in order to assess company's BPM maturity. They rated their organization's performance success factors using a 5-point scale, with a 1 representing "strongly disagree" and a 5 representing "strongly agree". Next, the slightly modified Organizational Culture Assessment Instrument was used to assess current organizational culture of observed company. Finally, the interviewers conducted an in-depth interview with questions related to the social BPM.

\section{Results analysis and discussion}

The total cumulative PPI score is calculated in order to measure BPM maturity. The average PPI is 46 - almost the highest on the PPI scale that runs from 10-50. The result 
shows that this company is at the upmost maturity level or "process management mastery" stage of BPM maturity. Further, the interviewees commented each of ten PPI framework factors. The PPI score on "alignment with strategy" success factor is 5: this company is aware that processes should be tightly linked to a strategy; its business processes are executed, managed and measured according to the strategic priorities and situations. The score on "holistic approach" is 5 . This shows that the approach to improvement efforts is done "through" a process perspective. BPM practice is institutionalized company-wide and a continuous improvement approach is evident. A "process awareness by management and employees" exists (the PPI score on this success factor is 4), the importance of managing processes when seeking performance goals is recognized by all employees in a company from top management to individual contributors, but the place for improvements still exists. The score on "portfolio of process management initiatives" is 5: key business processes are well-documented, business process repository has been developed, several business process improvement initiatives were finished and a new one is started. A standard approach to process design and analysis is utilized (the PPI score on "process improvement methodology" is 5), BPMN diagrams and Oracle Process Modeler software are used to model business processes. Process performance indicators and metrics are defined, but process measurement system is still not fully implemented. Consequently, the score on "process metrics" is 4. Strong efforts are made to focus process analysis and design efforts on delivering value to customer (the PPI score on "customer focus" success factor is 5). The process owners are assigned to several core business processes, their responsibilities and authorities are not well-defined, but they still do not monitor process metrics for continuous improvement efforts on a regular basis, thus the score on "process management" factor is 3. The observed company has the highest PPI score - 5 on the "information systems" factor. A potential of information system to provide support to business processes is fully recognized. People and cultural issues are effectively addressed when process changes are introduced; a collaborative IT platform is implemented, thus employees are enabled to suggest and create process content and context, or to share ideas and knowledge on business processes (the score on "change management" factor is 5). The PPI results for observed company are presented in figure 1 . 
Figure 1

Process Performance Index Results

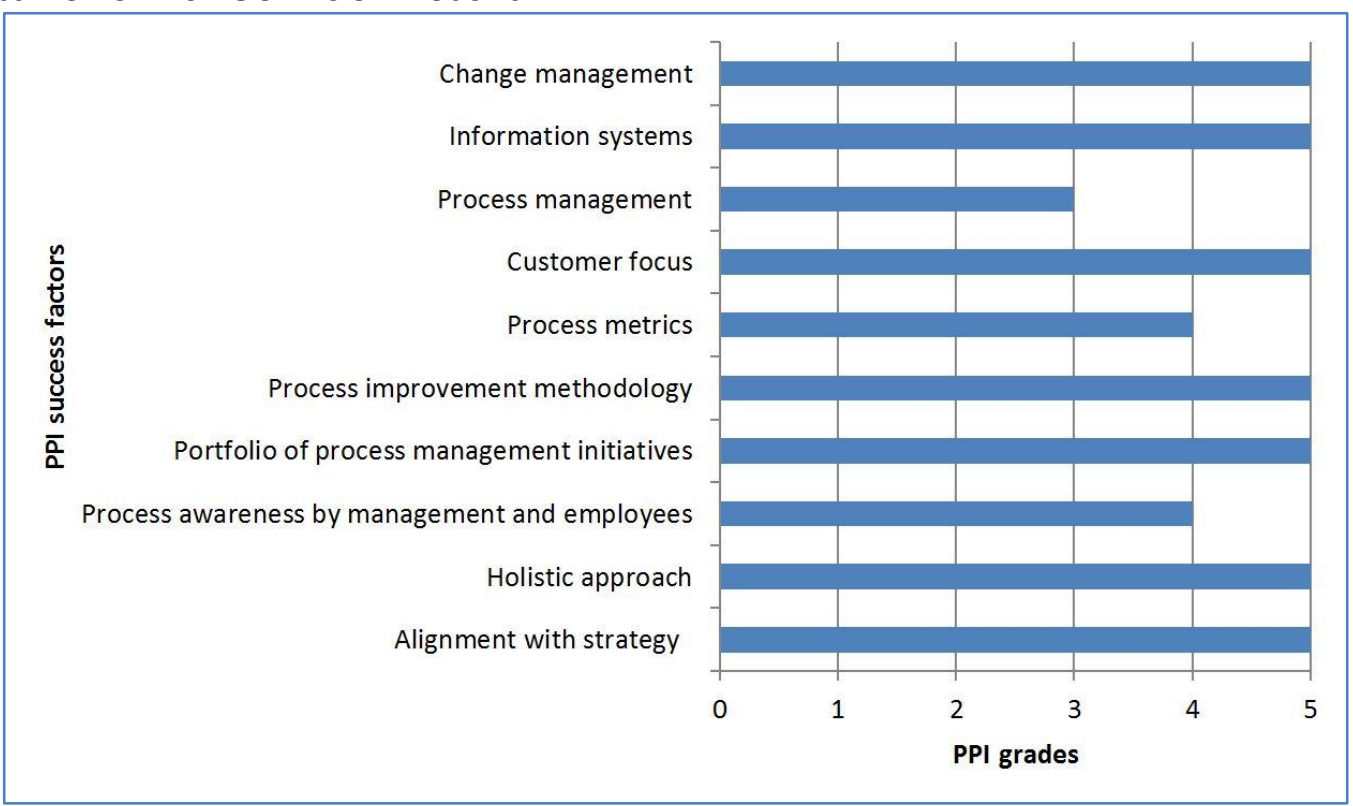

Source: Authors' illustration

For the purpose of this study, we have assessed only the current organizational culture of the observed company. OCAl results from the interview showed clan culture as dominant (with the score of 38 from 100) while adhocracy is at the second place with the score of 30 from 100.The OCAl results are presented in figure 2.

Figure 2

Organizational Culture Assessment Instrument Results

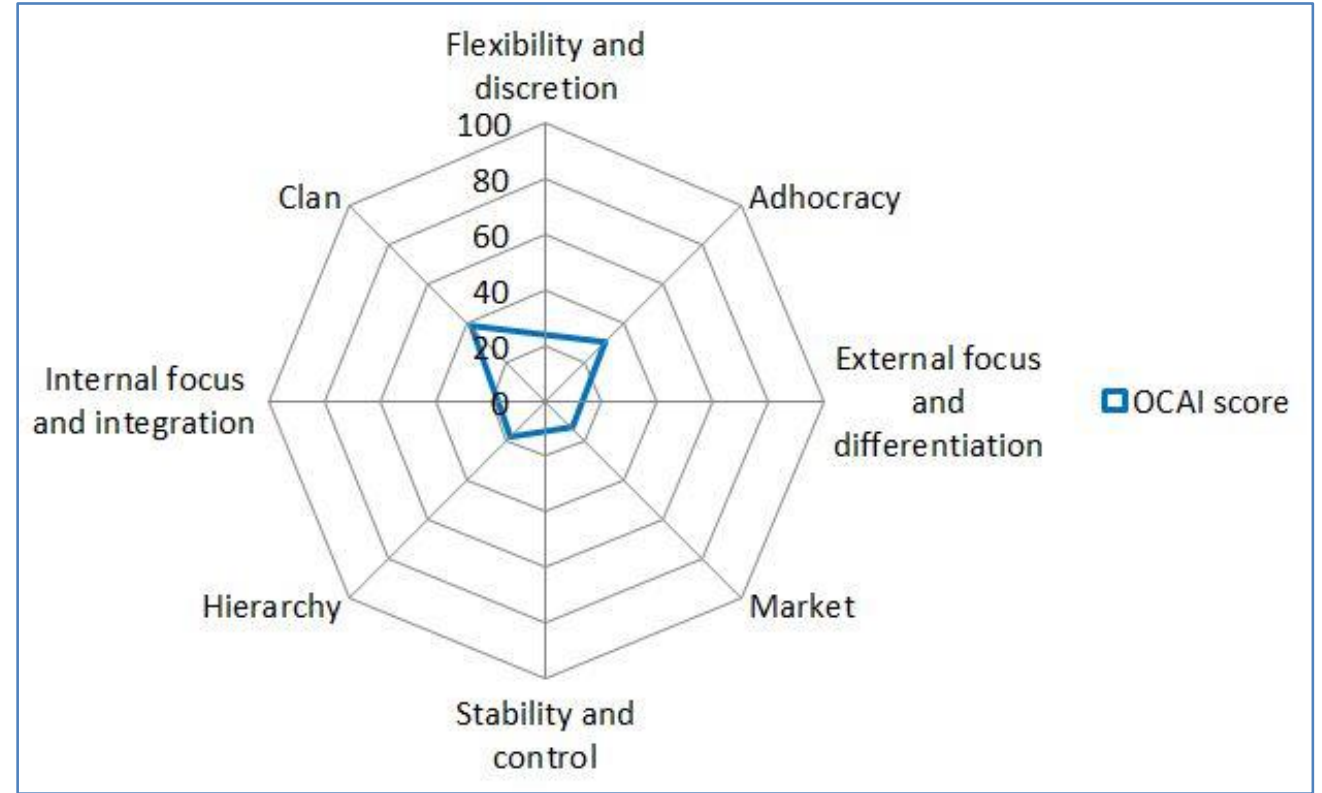

Source: Authors' illustration

This results, combined with high PPI score of observed company could be the step closer in confirmation of clan culture as the most favorable organizational culture for BPM, as indicated in Hribar and Mendling (2014). Clan culture is characterized by high commitment, teamwork, consensus, participation and a friendly workspace 
while defining success in terms of concern for people and internal climate (Cameron \& Quinn, 2006). Furthermore, the core values within clan culture organizations are loyalty, high cohesion, morale and tradition, emphasizing the long-term benefit of individual development (Cameron \& Quinn, 2006). On the other hand, the adhocracy culture is characterized by innovativeness, readiness for change, meeting new challenges and risk taking while working in highly dynamic, creative and entrepreneurial workspace (Cameron and Quinn, 2006).

An in-depth interview revealed high level of using social software for BPM purposes within the observed company. Employees are self-organized and interactively design and change business processes in bottom-up fashion. Their BPM approach highly relies on the idea of giving all participants the same rights to contribute to business process design and change which are based on the ideas and knowledge of a group rather than individual experts or external influences. Moreover, some of their stakeholders use social software and Enterprise 2.0 tools (e.g. blogs, wikis, social networks, Lync, Yammer) to suggest and create process content and context.

\section{Conclusion}

This paper presented a case study of one Croatian IT consultant and software implementation company which has knowledge intensive processes. This company use social BPM in order to deal with process change and optimization. Having in mind the characteristics of the clan culture which is dominant in the presented company, successful use of social BPM does not come as a surprise.

This paper extends the body of knowledge regarding the role of organizational culture in BPM. However, it has some limitations as well. Since the study has been limited to a single case study, it is not possible to generalize our findings. Further research in this area should be made in order to correct the limitations of this study and shed some more light on the role of the organizational culture in BPM.

\section{References}

1. Alibabaei, A., Aghdasi, M., Zarei, B., Stewart, G. (2010), „The role of culture in business process management initiatives", Australian Journal of Basic and Applied Sciences, Vol. 4 No. 7, pp. 2143-2154.

2. Bider, I., Halpin, T., Krogstie, J., Nurcan, S., Proper, E., Schmidt, R. (2010), Enterprise, Business-process and Information Systems Modeling, Springer, Berlin.

3. Bögel, S., Stieglitz, S., Meske, C. (2013), "Bringing together BPM and Social Software", 19th Americas Conference on Information Systems (AMCIS), Chicago, USA.

4. Brambilla, M., Fraternali, P., Ruiz, C. K. V. (2012), "Combining social web and BPM for improving enterprise performances: the bpm4people approach to social", Proceedings of the 21st World Wide Web Conference, Lyon, France, 16-20April 2012, pp. 223-226.

5. Bruno, G., Dengler, F., Jennings, B., Khalaf, R., Nurcan, S., Prilla, M., Sarini, M., Schmidt, Silva, R. (2011), "Key challenges for enabling agile BPM with social software", Journal of Software Maintenance and Evolution: Research and Practice, 23, pp. 297-326.

6. Buh, B., Kovačič, A., Indihar Štemberger, M. (2015), Critical success factors for different stages of business process management adoption-a case study, Ekonomska Istraživanja, Vol.28, No.1, pp. 243-258.

7. Cameron, K. S., Quinn, R. E. (2006), Diagnosing and changing organizational culture: Based on the competing values framework, Jossey-Bass, San Francisco, USA.

8. Cummins, F. A. (2008), Building the Agile Enterprise: with SOA, BPM and MBM, Morgan Kaufmann Pub., Burlington MA, USA. 
9. Dengler, F., Koschmider, A., Oberweis, A., Zhang, H. (2010), "Social software for coordination of collaborative process activities", Third Workshop on Business Process Management and Social Software, LNBIP, Hoboken, NJ, pp. 396-407.

10. Erol, S., Granitzer, M., Happ, S., Jantunen, S., Jennings, B., Johannesson, P. (2010), "Combining BPM and social software: contradiction or chance?". Journal of Software Maintenance and Evolution: Research and Practice, Vol. 22 No. 6/7, pp. 449-476.

11. Harmon, P. (2007), Business Process Change: A Guide for Business Managers and BPM and Six Sigma Professionals, Morgan Kaufman Publishers, San Francisco.

12. Harmon, P. (2009), "Process maturity models", available at: http://www.bptrends.com/publicationfiles/spotlight_051909.pdf (1/20/2016).

13. Hribar, B., Mendling, J. (2014), "The correlation of organizational culture and success of BPM adoption", in: Proceedings of the European Conference on Information Systems (ECIS), 2014, Tel Aviv, Israel, June 9-11, 2014.

14. Khider, H., Benna, A. (2015), "Social Business Process Management Approaches - A Comparative Study", International Conference on Enterprise Information Systems (ICEIS) 2015, Barcelona, Spain, pp. 340-345.

15. Markus, M.L., Majchrzak, A., Gasser, L. (2002), "A design theory for systems that support emergent knowledge processes", MIS Quarterly, Vol.26, No.3, pp.179-212.

16. Meske, C. and Stieglitz, S. (2013), "Adoption and Use of Social Media in Small and Medium-sized Enterprises", The 6th Practice-Driven Research on Enterprise Transformation (PRET) Conference, Utrecht, pp. 61-75.

17. Nurcan S., Schmidt R., Soffer P. (2008), "BPMDS'08 business process life-cycle: design, deployment, operation \& evaluation", CAiSE'08 Workshop Proceedings, Montpellier, France, 17.

18. Rangiha, M.E., Karakostas, B. (2013), "Goal-Driven Social Business Process Management", The Science and Information Organization, Science and Information (SAI) Conference, 7 - 9 October 2013, London, UK, pp. 894 - 901.

19. Rangiha, M.E., Karakostas, B. (2014), "A Goal-Oriented Social Business Process Management Framework", International Journal of Social, Behavioral, Educational, Economic, Business and Industrial Engineering, Vol. 8 No. 9, pp. 2951-2957.

20. Rosemann, M., deBruin, T. (2005), "Application of a Holistic Model for Determining BPM Maturity", available at: http://www.bptrends.com/publicationfiles/0205\%20WP\%20Application\%20of\%20a\%20Holistic\%20Model-\%20Rosemann-Bruin\%20\%E2\%80\%A6.pdf (3/29/2016).

21. Rosemann, M., vom Brocke, J. (2015), "The six core elements of business process management", in: Handbook on Business Process Management 1, Springer, 2nd edition, pp. 105-122.

22. Rummler-Brache Group, (2004), "Business process management in US firms today", available at: http://www.rummlerbrache.com/upload/files/PPI_Research_Results.pdf (12/5/2015)

23. Schmidt, R., Nurcan, S. (2009), "BPM and Social software", Business Process Management Workshops, Ulm, Germany, pp. 625-634.

24. Schmiedel, T., vom Brocke, J., Recker, J. (2013), "Which cultural values matter to business process management? Results from a global Delphi study", Business Process Management Journal, Vol. 19 No. 2, pp. 292-317.

25. Sidorova, A., Isik, O. (2010), "Business process research: a cross-disciplinary review", Business Process Management Journal, Vol. 16 No. 4, pp. 566-597.

26. Yin, R. (1994). "Case Study Research: Design and Methods". Sage Publications, Thousand Oaks, CA.

27. Zairi, M. (1997), "Business process management: a boundaryless approach to modern competitiveness", Business Process Management Journal, Vol. 3 No. 1, pp. 64-80. 


\section{About the authors}

Vesna Bosilj Vukšić is a professor of Business Process Management, Knowledge Management and Business Computing at the Faculty of Economics and Business, University of Zagreb, at the Department of Informatics. Her current research interests are in business process and knowledge management. The author can be contacted at vbosilj@efzg.hr.

Dalia Suša is a teaching and research assistant at the Department of Informatics, Faculty of Economics and Business, University of Zagreb, where she is also enrolled in a postgraduate doctoral study program. Her main research interests are BPM, organizational culture, unified communications, Web 2.0/3.0 technologies and digital literacy. The author can be contacted at dsusa@efzg.hr.

Anita Lovric is Executive director for consulting and agile system at company Infodom. Mainly works on national and international projects as a specialist for strategy planning and adaptation, business process management, business model and enterprise architecture development. The author can be contacted at anita.lovric@infodom.hr. 